\title{
ROMANIAN
}

NEUROSURGERY

Vol. XXXIV | No. 2 June 2020

The efficacy of adalimumab on experimentally induced spinal cord ischemia-reperfusion injury

Yasar Karatas, Mehmet Fatih Erdi, Bulent Kaya, Fatih Keskin, Ibrahim Kılınç, Mehmet Uyar, Sabiha Serpil Kalkan, Emir Kaan Izci, Erdal Kalkan 


\section{The efficacy of adalimumab on experimentally induced spinal cord ischemia-reperfusion injury}

\author{
Yasar Karatas ${ }^{1}$, Mehmet Fatih Erdi ${ }^{2}$, \\ Bulent Kaya ${ }^{1}$, Fatih Keskin², İbrahim Kılınç², \\ Mehmet Uyar ${ }^{2}$, Sabiha Serpil Kalkan², Emir Kaan \\ Izci $^{3}$, Erdal Kalkan ${ }^{1}$ \\ 1 Medova Hospital, Konya, TURKEY \\ 2 Necmettin Erbakan University, Meram Medical \\ Faculty, Konya, TURKEY \\ 3 Meram Training and Research Hospital, Department of \\ Neurosurgery, TURKEY
}

\begin{abstract}
Objective: Paraplegia is a dangerous complication of thoracoabdominal aortic surgery. Various studies have been conducted on the prevention of this complication and some spinal cord protection methods have been proposed. However, there is not any modality that prevent the development of paraplegia certainly. In the I/ R period, primary injury triggers secondary injury due to increased inflammation, apoptosis and free radical formation. In this study, we evaluated that the neuroprotective effect of adalimumab in spinal cord ischemia-reperfusion injury.

Materials and Methods: In total, 24 adult New Zealand rabbits were divided into three groups: Group 1, control; Group 2, ischemia-reperfusion by infrarenal aortic clamping; Group 3, adalimumab treated followed by ischemia. Tissue and plasma tumor necrosis factor alpha, interleukin 6, interleukin 10, thiobarbituric acid reactive substance, total oxidant status and total antioxidant status levels were analyzed as a marker of inflammation and oxidation. Histopathological evaluation of the tissues was performed, and apoptosis was evaluated by TUNNEL method.

Results: I/R injury significantly increases plasma and spinal cord tissue at TNF alpha, TOS, TBARS, IL6 levels and reduces plasma and spinal cord tissue to TAS and IL10 levels. Adalimumab treatment significantly reduces plasma and spinal cord tissue to TNF alpha, TOS, TBARS, IL6 and increases plasma and tissue to TAS and IL10 levels.

Conclusion: Adalimumab treatment significantly reduces the spinal cord neuronal damage score and the number of apoptotic cells. This paper aims to demonstrate the important neuroprotective effects of adalimumab on rabbit spinal cord I/R injury.
\end{abstract}

\section{INTRODUCTION}

Spinal cord reperfusion injury is described as cell death of neurons although improvement of blood supply of spinal cord after ischemia. It usually occurs because of oxygen free radical-induced lipid peroxida-

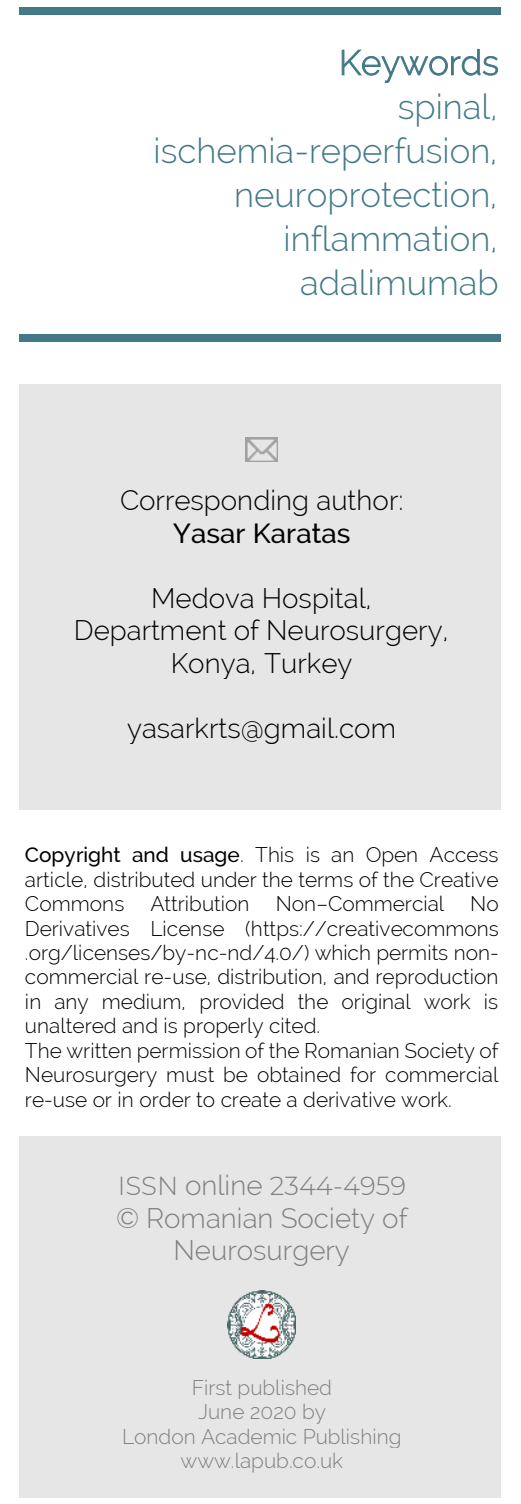


tio, leukocyte activation, inflammation and neuronal apoptosis. Although many clinical treatments of spinal cord injury have been provided in recent years, the results are far from satisfactory [1]. Paraplegia is a serious complication that can occur in a patient undergoing thoracoabdominal aortic surgery and has been seen in $2.4-40 \%$ of the patients [2]. Factors that cause this complication are: impaired arterial blood flow and I/R injury of the spinal cord due to collateral supplier damage, perfusion insufficiency, prolonged aortic crossclamping time, intraoperative proximal hypertension, high cerebrospinal fluid (CSF) pressure and postoperative hypotension [3]. Neurological injury that occurs after impact is called primary injury. Primary injury triggers secondary injury with increased inflammation, apoptosis and the formation of free radicals that have serious effects on outcome. Various pharmacological agents have been used to prevent secondary damage at different success rates [4]. However, there is no complete treatment of secondary injuries.

Tumor necrosis factor is an important immunoregulator molecule that act important role in central nervous system events such as stroke [5]. There are two type of TNF molecule. First type of TNF molecule is transmembrane TNF which acts through cell-to-cell contact to initiate juxtracrine signaling and is important not only for cellular transmission in the natural immune system but also for functional improvement and axonal preservation $[6,7]$. The second type of TNF molecule is soluble TNF that acts in a paracrine manner and is a substantial mediator of both acute and chronic inflammation [8].

Adalimumab is a potent TNF alpha blocker. It suppresses TNF- $\alpha$ and IL-6, initiate to reduction or inhibition of the inflammatory process [9]. Many studies have shown that TNF- $\alpha$ and IL- 6 are elevated during $I / R$ and that they are responsible for activation of the cell death by apoptosis [10]. Recently, the neuroprotective impacts of anti-TNF treatment have been studied in a model of focal cerebral ischemia and beneficial effects have been stated [11].

The aim of this study was to investigate the neuroprotective impacts of adalimumab on rabbit spinal cord I/R injury model.

\section{MATERIALS AND METHODS}

This research was carried out in the Experimental
Medicine Application and Research Center of Necmettin Erbakan University. The experimental protocol was assessed and confirmed by the Ethics Review Committee of Necmettin Erbakan University. The animals were kept at a room temperature (18$21^{\circ} \mathrm{C}$ ) and fed on a standard diet. A 12 -h light-dark cycle (08:00 -20:00 hours light/20:01-07:59 hours dark) was preserved. The animals were able to get as much food and water as they wanted.

\subsection{Groups}

Twenty-four adult New Zealand rabbits were randomly separated into three groups: Group 1, control group $(n=8)$; Group 2, ischemia-reperfusion (I/R) group and group $3(n=8)$, l/R injury+ adalimumab (40 mg/kg, ip, single dose) treatment group.

All rabbits were anesthetized by intramuscular (i. $\mathrm{m}$.) injection of ketamine $(50 \mathrm{mg} / \mathrm{kg}$ ) (Ketalar, ParkeDavis, Eczacıbaşı, Istanbul, Turkey) and xylazine (10 $\mathrm{mg} / \mathrm{kg}$ ) (Rompun, Bayer, Istanbul, Turkey) and permitted to breathe during the procedure. An intravenous catheter was placed in the auricular vein of the animals and preoperative cefazolin $10 \mathrm{mg} / \mathrm{kg}$ (Cefamezin, Eczacıbası, Istanbul, Turkey) was given as a single dose. As maintenance, $0.9 \% \mathrm{NaCl}(20 \mathrm{ml} / \mathrm{h})$ was given throughout the experiment.

All rabbits underwent laparotomy in supine position. Aortic cross-clamp was not applied to group 1. In group 2 and 3 the abdominal aorta was detected and dissected carefully from the beginning of the left renal artery by transperitoneal approach. Five minutes before occlusion, $100 \mathrm{lU} / \mathrm{kg}$ heparin was given intravenously. The aorta was then crossclamped using an aneurysm clip with a closing force of 70 grams (Yasargil FE 721, Aesculap). The clipping site was just below the origin of the left renal artery. Pulsation of the femoral artery disappeared after occlusion. The aneurysm clip was removed 30 minutes later, and aortic pulsation was restored. Neither aortic nor caval hemorrhage were observed during surgery. Before closure, rabbits of group 3 received single dose intraperitoneal $40 \mathrm{mg} / \mathrm{kg}$ adalimumab treatment. After the closure of laparotomy all rabbits awoke and returned to their cages. The animals were followed neurologically, and motor inefficiency and recovery rates were recorded. Seventy-two hours later, all rabbits were reanesthetized by intramuscular (i. m.) injection of ketamine (50 mg/kg) (Ketalar, Parke-Davis, Eczacıbaşı, Istanbul, Turkey) and xylazine (10 mg/kg) 
(Rompun, Bayer, Istanbul, Turkey). Blood samples were taken from auricular veins for biochemical examination. For histopathological examination spinal cord samples were taken from lumbar spinal cord segments between L4-L6 by laminectomies and the rabbits were sacrificed.

\subsection{Biochemical Analysis}

Venous blood samples were collected by centrifugation at $4^{\circ} \mathrm{C}$ and $1,000 \mathrm{~g}$ for 10 minutes to remove plasma. Plasma samples were kept at $-80^{\circ} \mathrm{C}$ until the parameters were studied.

Spinal cord tissue samples were provided in $\mathrm{pH}$ $7.450 \mathrm{mM}$ phosphate buffer and kept at $-80^{\circ} \mathrm{C}$ until they were analyzed. The thawed tissue samples were weighed and homogenized in ice using a mechanical homogenizer and an ultrasonic homogenizer in a 10 fold (w / v) cold phosphate buffer (50 mM, pH: 7.4). The supernatants were separated by centrifuging the homogenates for $10 \mathrm{~min}$ at $4^{\circ} \mathrm{C}$ and $10.000 \mathrm{~g}$. Pierce bicinchoninic acid-BCA (Thermo Scientific, Illinois, USA) was used to measure spectrophotometrically plasma and spinal cord tissue total oxidant (TOS) and antioxidant status (TAS) (Rel Assay Diagnostics, Gaziantep, Turkey), thiobarbituric acid reactive substances (TBARS) (Oxford Biomedical Research, Missouri, USA) and tissue protein levels. Plasma and spinal cord tissue IL-6, IL-10 and TNF alpha levels were examined by using ELISA antigens that were intrinsic to rabbits (Elabscience Biotechnology Co., Wuhan, China).

\subsection{Histopathological Studies}

Spinal cord samples were stabilized by $10 \%$ formaldehyde for two days and then embedded in paraffin blocks. After dehydration, coronal sections of the spinal cord segment were severed at a thickness of $4 \mu \mathrm{m}$ and stained with hematoxylin and eosin (HE) in order to examine the structural changes. Gray matter was checked in five different areas in each section. Depending on the degree of inflammation, hemorrhage, axonal swelling, congestion, neuronal degeneration and vacuolization of the spinal cord, the light microscopic findings were graded on a scale ranging from 0 to 3 , corresponding to "no change", "mild", "moderate" and "severe" changes, respectively. The histopathological score was calculated for each spinal cord sample [12].
Apoptotic cells were labeled using an ApopTag In Situ Apoptosis Detection Kit (Millipore). DNA fragments in spinal cord regions were altered by the action of terminal deoxynucleotidyl transferase. The manufacturer's instructions were followed during procedures. In each section five dark visual fields were randomly chosen, and the TUNEL-positive neurons and the total number of neurons in the selective visual fields was counted. TUNEL-positive index (the TUNEL-positive to whole neurons ratio) was computed. Eight sections from each group were used for measurement, and five high-powered visuals were indiscriminately picked from every section to carry out measurement of the TUNELpositive indices [13].

\subsection{Statistical analysis}

Data were analyzed using SPSS (version 24.0, SPSS Inc.) and expressed as mean \pm SD. Comparisons were made by the Kruskal-Wallis test. Differences among the groups were evaluated by the MannWhitney $U$ test. A $p<0.05$ was considered statistically significant. Histopathological score and TUNEL positive cell count were contrasted using a one-way analysis of variance (ANOVA) with TUKEY test.

\section{RESULTS}

\subsection{Histopathological evaluation}

I/R injury significantly increased the spinal cord neuronal damage score and apoptotic cell count. Adalimumab treatment statistically substantially decreased spinal cord neuronal injury score and apoptotic cell count $(p=0)$. Large motor cells were observed in anterior horn of the spinal cord in the control group (Figure 1A). No changes were observed in the neurons. The most serious injury was seen in ischemia-reperfusion group in spinal cord in $\mathrm{HE}$ sections (Figure 1B, C, D). Necrosis, hemorrhage and congestion were noticed in ischemia-reperfusion group. Nissl substances disappeared in necrotic neurons. In addition, neuropil vacuolization and tissue loss were observed in the gray matter (Figure $1 E, F, G)$. Compared with control group, it was noticed that histopathological score rose in ischemiareperfusion group. Histopathological alterations and score significantly reduced in adalimumab treatment group (Fig 1H). Myelin swelling determined in white matter in ischemia group and the adalimumab group had less myelin swelling compared to the ischemia group. (Figure 2A, B, C). TUNEL positive cells count 
increased in I/R group when compared with control group (Figure 3A, B). Adalimumab treatment

\section{$\underline{\mathbf{A}}$}

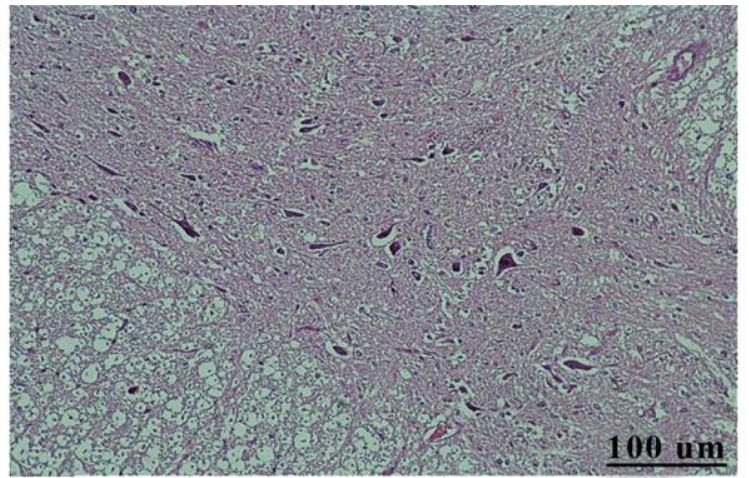

$\underline{\mathrm{C}}$

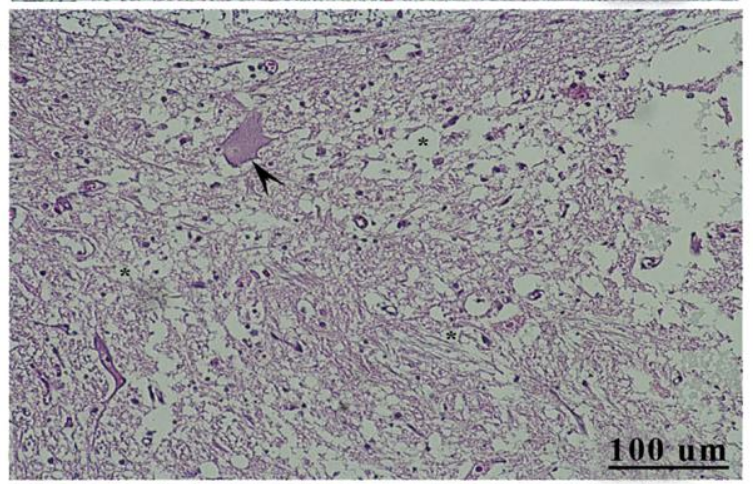

$\underline{\mathbf{E}}$

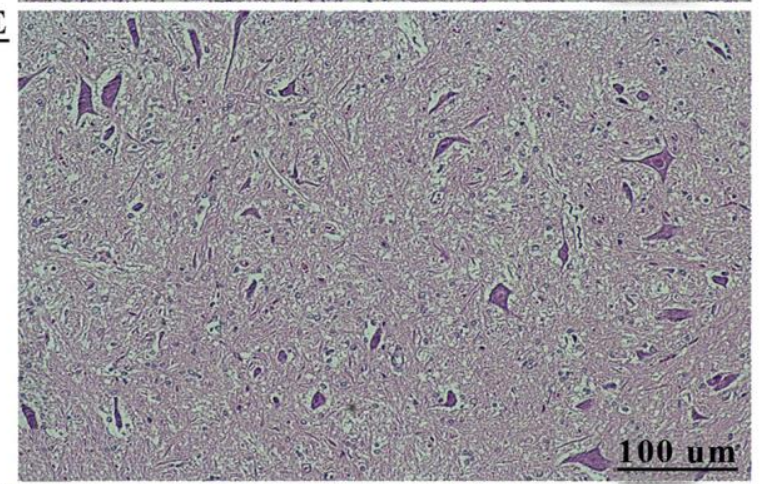

$\underline{\mathbf{G}}$

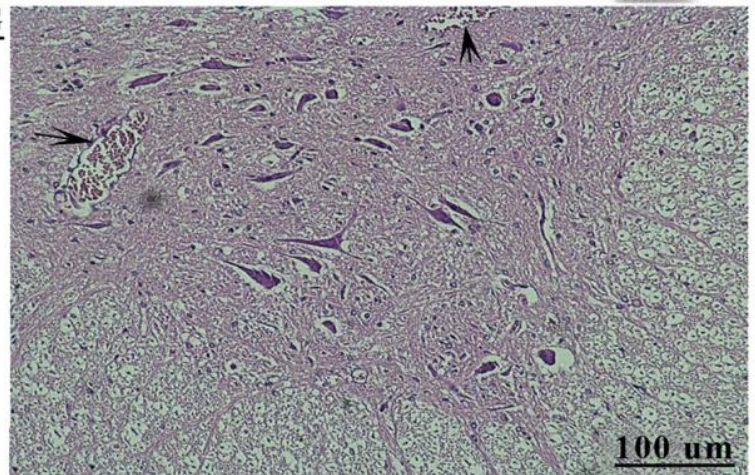

decreased TUNEL positive cells count (Figure 3C). Figure 3D showed differences among groups.
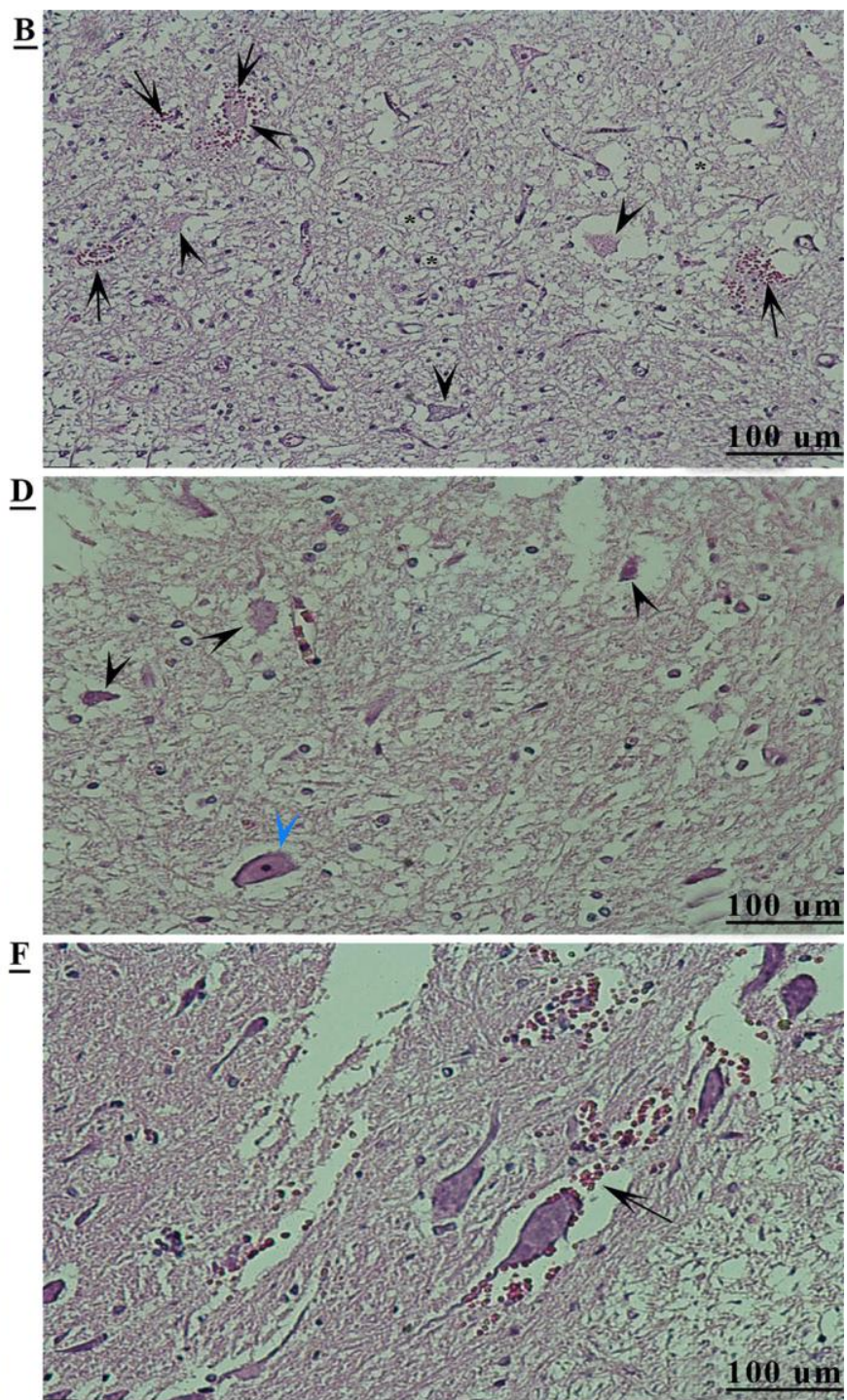

$\underline{\mathbf{H}}$

Histopathology core

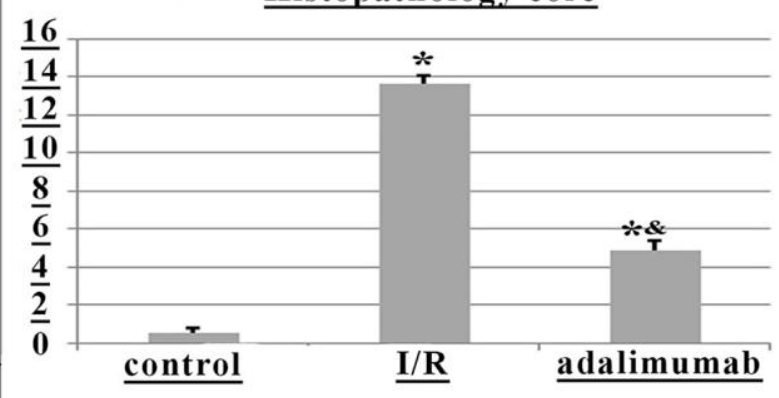

Figure 1. Histopathological photomicrographs of spinal cord tissue stained HE A: Control Group : Neurons in grey matter and White matter B: Necrotic neurons in Ischemia-Reperfusion Group (black arrow), Haemorrhage ve (arrows), *:vacuoles. C: chromatolyses in Ischemia-Reperfusion Group (arrow head), *:vacuoles. D: pyknosis in Ischemia-Reperfusion Group (arrows), necrotic neurons (arrows). E: Normal neurons in Adalimumab treatment group F: haemorrhage in Adalimumab treatment group (arrow). G: Congetion in Adalimumab treatment group (arows). H: Histopathological assessment of spinal cord, (* $\mathrm{P}<0.05$, compared to group $1 ; \& \mathrm{P}<0.05$, compared to group 2). 

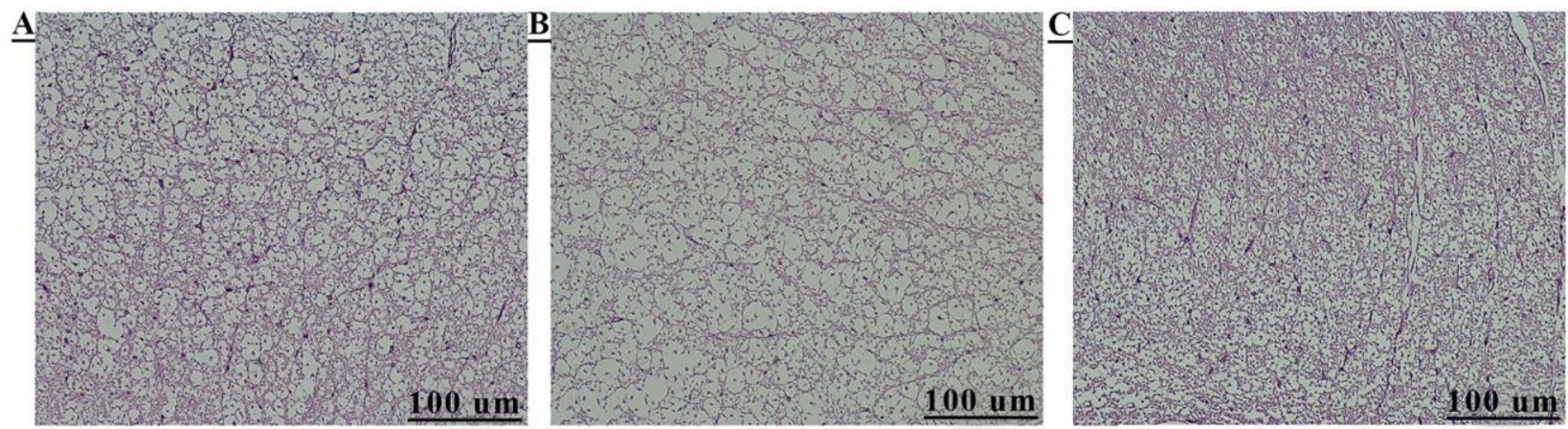

Figure 2. Histopathological photomicrographs of white matter stained HE A: Control Group. B: Ischemia-Reperfusion Group C: Adalimumab treatment group.
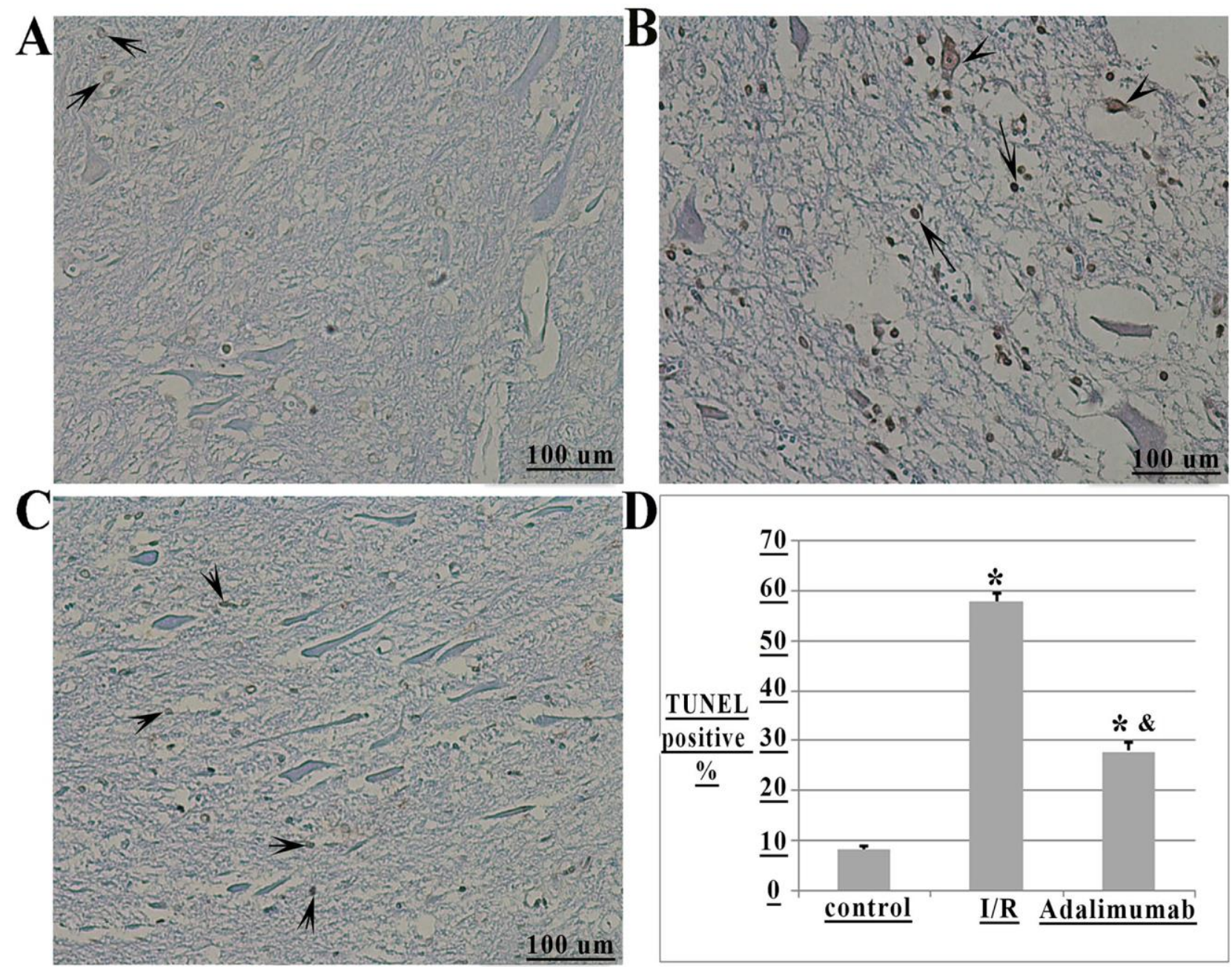

Figure 3. Representative spinal cord sections stained in the TUNEL assay. A: Control group, B:Ischemia-Reperfusion group C: Adalimumab treatment group .D: Comparison of groups according to TUNEL-positive cells in spinal cord, (* $\mathrm{P}<0.05$, compared to group 1; \&P < 0.05, compared to group 2).

\subsection{Biochemical evaluation}

I/R injury significantly increased the plasma and spinal cord tissue TNF alpha, TOS, TBARS, IL6 levels and reduced the plasma and spinal cord tissue TAS and IL10 levels. Adalimumab treatment significantly decreased the plasma and spinal cord tissue TNF alpha, TOS, TBARS, IL6 levels and raised plasma and tissue TAS and IL10 levels (Figure 4, Figure 5). 

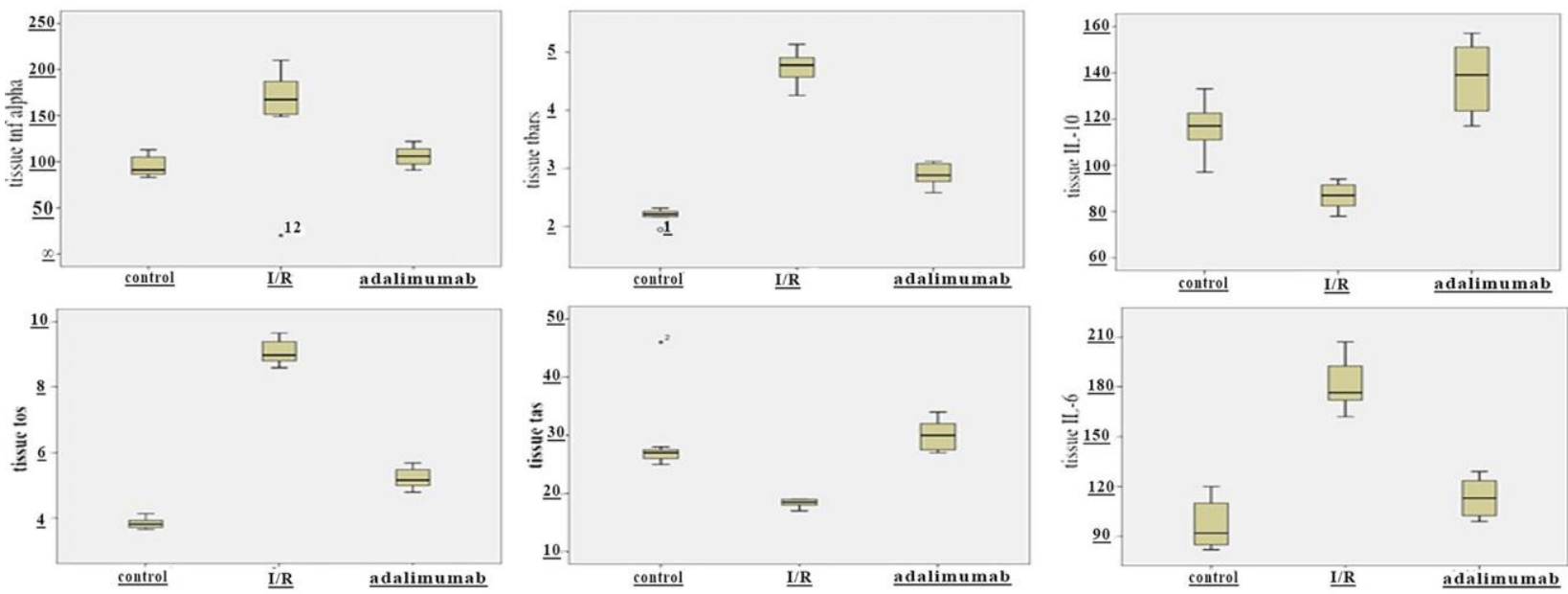

Figure 4. The effects of adalimumab on plasma levels of TAS,TOS,TBARS,TNF ALPHA,IL6,IL10.
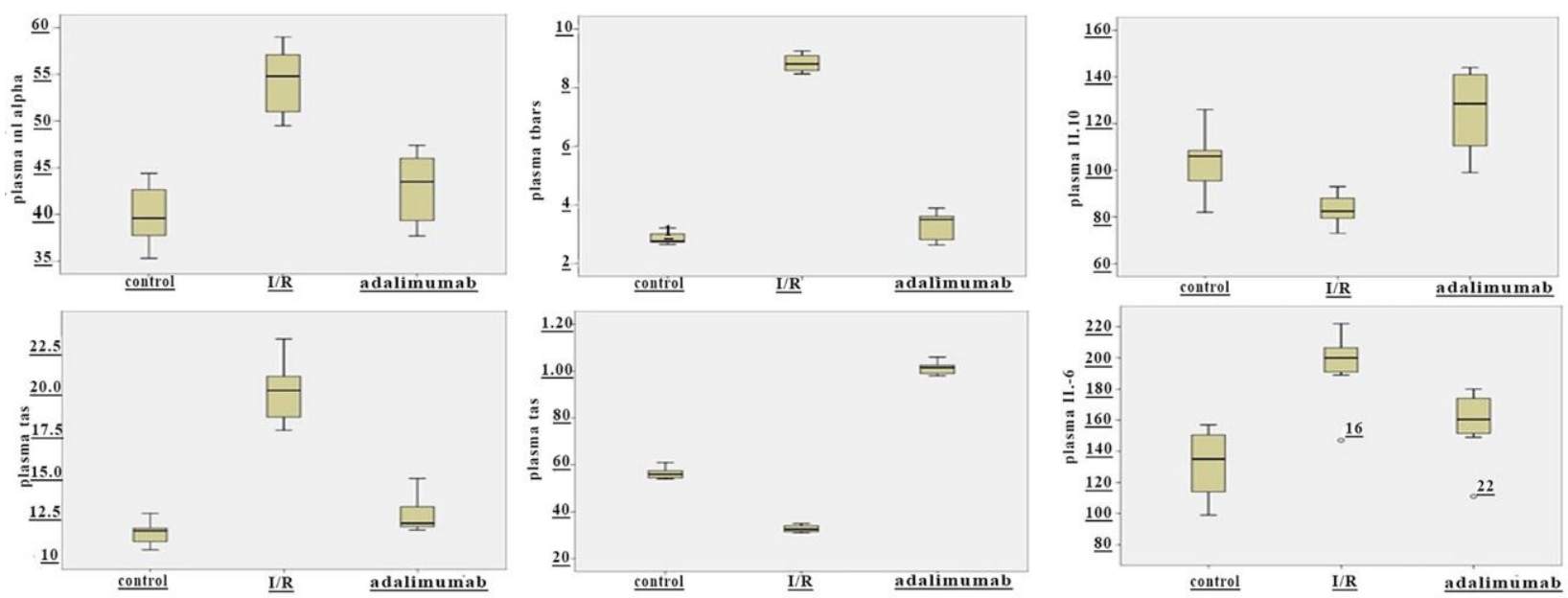

Figure 5. The effects of adalimumab on tissue levels of TAS,TOS,TBARS,TNF ALPHA,IL6,IL10.

\section{DISCUSSION}

Neural tissues can be said to be very sensitive to ischemia. I / $\mathrm{R}$ damage of the spinal cord during thoracoabdominal vascular surgery can cause serious discomfort such as paraplegia. Primary injury triggers secondary injury with increased inflammation, apoptosis and free radical formation during the I / R period [14]. Secondary injury may result in endothelial dysfunction and increase vascular permeability that promotes migration and activation of immune cells. These activated immune cells infiltrates the related area and secrete some proinflammatory cytokines. Enhanced inflammation causes reactive oxygen species produce and induces lipid peroxidation which causes injury in the ultrastructure of neural cell membranes and hinders their critical functions [15].
The spinal cord is very sensitive to ischemia because it has its own anatomical features. "The infrarenal aortic cross-clamp" method used in this study leads to severe spinal cord injury. It was first described by Liang et al. as an experimental method $[16,17]$. Rabbits have segmental blood supply in their lumbosacral spinal cord. Thus, rabbit model of spinal cord I/R injury is commonly used. It is clear that there are many causes of paraplegia. Long-term ischemia, interruption of critical intercostal and lumbar arteries, decrease in spinal cord perfusion pressure and postoperative reperfusion injury are some of these reasons [18]. Therefore, this method is thought to be appropriate to imitate the complications of aortic surgery.

High levels of plasma and spinal cord tissue TNF alpha, TOS, TBARS and IL6 in I/R group signifies 
increased inflammation and oxidative stress. Neuronal damage score and apoptotic cell count increase after $\mathrm{l} / \mathrm{R}$ injury. Adalimumab treatment significantly improves biochemical and histopathological adverse impacts of I/R injury.

\section{CONCLUSION}

In this study, it was found that adalimumab had significant neuroprotective effects on rabbit spinal cord I/R injury. After I / R injury, high inflammation and oxidative stress were successfully reversed by adalimumab, and the worse effects of biochemical, histopathological and neurological I / R damage were mitigated. Further studies are needed to carry out this treatment in clinical practices.

\section{REFERENCES}

1. Kieffer E, Chiche L, Cormier E, Guegan E. Recurrent spinal cord ischemia after endovascular stent grafting for chronic traumatic aneurysm of the aortic isthmus. Journal of Vascular Surgery 2007; 45: 831-833.

2. Coselli JS, LeMaire SA, Conklin LD, Koksoy C, Schmittling ZC. Morbidity and mortality after extent II thoracoabdominal aortic aneurysm repair. Ann Thorac Surg. 2002; 73(4):1107-15, http://dx.doi. org/10.1016/S0003-4975(02)03370-2.

3. Kocogullari CU, Becit N, Erkut B, Keleş MS, Ceviz M, Ates A, Gündogdu C, Kaygın MA, Kocak H. Prevention of reperfusion injury of the spinal cord in aortic surgery: an experimental study. Surg Today 2008; 38(3): 237-44.

4. Junk AK, Mammis A, Savitz SI, Singh M, Roth S, Malhotra S, Rosenbaum PS, Cerami A, Brines M, Rosenbaum DM. Erythropoietin administration protects retinal neurons from acute ischemia-reperfusion injury. Proc Natl Acad Sci USA 2002; 99: 10659- 10664.

5. Lambertsen $\mathrm{KL}$, Biber $\mathrm{K}$, Finsen B. Inflammatory cytokines in experimental and human stroke. J Cereb Blood Flow Metab 2012; 32: 1677-1698.

6. Alexopoulou L, Kranidioti K, Xanthoulea S, Denis M, Kotanidou A, Douni E, Blackshear PJ, Kontoyiannis DL, Kollias G. Transmembrane TNF protects mutant mice against intracellular bacterial infections, chronic inflammation and autoimmunity. Eur J Immunol 2006; 36: 2768-2780.

7. Brambilla R, Ashbaugh J, Magliozzi R, Dellarole A, Karmally S, Szymkowski DE, Bethea JR. Inhibition of soluble tumour necrosis factor is therapeutic in experimental autoimmune encephalomyelitis and promotes axon preservation and remyelination. Brain 2011; 134: 2736-2754.

8. Ruuls SR, Hoek RM, Ngo VN, McNeil T, Lucian LA, Janatpour MJ, Korner $\mathrm{H}$, Scheerens $\mathrm{H}$, Hessel EM, Cyster JG, McEvoy LM, Sedgwick JD. Membrane-bound TNF supports secondary lymphoid organ structure but is subservient to secreted TNF in driving autoimmune inflammation. Immunity 2001; 15:5 33-543.

9. McGovern JL, Nguyen DX, Notley CA, Mauri C, Isenberg DA, Ehrenstein MR. Th17 cells are restrained by Treg cells via the inhibition of interleukin- 6 in patients with rheumatoid arthritis responding to anti-tumor necrosis factor antibody therapy. Arthritis Rheum 2012; 64: 31293138.

10. Xu YF, Liu M, Peng B, Che JP, Zhang HM, Yan Y, Wang GC, Wu YC, Zheng JH. Protective effects of SP600125 on renal ischemia-reperfusion injury in rats. J Surg Res 2011; 169: 77-84.

11. Clausen BH, Degn $M$, Martin NA, Couch $Y$, Karimi $L$, Ormhøj M, Mortensen ML. Systemically administered anti-TNF therapy ameliorates functional outcomes after focal cerebral ischemia. J Neuroinflammation. 2014; 12: 11:203. doi: 10.1186/s12974-014-0203-6.

12. Kishimoto T, Akira S, Narazaki M, Taga T. Interleukin-6 family of cytokines and gp130. 1995; 86:1243-54.

13. Gürer B, Kertmen H, Kasim E, Yilmaz ER, Kanat BH, Sargon MF, Arikok AT, Ergüder BI, Sekerci Z. Neuroprotective effects of testosterone on ischemia/reperfusion injury of the rabbit spinal cord. Injury. 2015; 46(2): 240-8.

14. Klune JR, Tsung A. Molecular biology of liver ischemia/reperfusion injury: Established mechanisms and recent advancements. Surg Clin North Am 2001; 90: 665-77.

15. Chan $\mathrm{PH}$. Role of oxidants in ischemic brain damage. Stroke. 1996; 27(6): 1124-9.

16. Liang Y, Yang Q-H, Yu X-D, Jiang D-M. Addictive effect of tetramethlpyrazine and deferoxamine in the treatment of spinal cord injury caused by aortic crossclamping in rats. Spinal Cord 2011; 49: 302-306; doi: 10.1038/sc.2010.113; published online 14 September 2010.

17. Shechter $R$, London $A$, Varol $C$, Raposo $C$, Cusimano $M$, Yovel G, Rolls A, Mack M, Pluchino S, Martino G, Jung S, Schwartz M. Infiltrating blood-derived macrophages are vital cells playing an anti- inflammatory role in recovery from spinal cord injury in mice. PLoS Med 2009; 6(7): e1000113. doi:10.1371/journal.pmed.1000113.

18. Sahin MA, Onan B, Guler A, Oztas E, Uysal B, Arslan S, Demirkilic U, Tatar H. Cilostazol, a type III phosphodiesterase inhibitor, reduces ischemia/ reperfusion-induced spinal cord injury. Heart Surg Forum 2011; 14: 171-177. 